\title{
Modelling in Archaeology: Computer Graphic and Other Digital Pasts
}

\section{Graeme Earl}

Archaeological Computing Research Group, University of Southampton, UK

\section{Introduction}

Computer graphic modelling forms an increasing part of archaeological practice, implicated in modes of recording objects and spaces, the interpretation of types, the management of three-dimensional information, creation of artificial experiences of place for interpretation, and the representation of archaeological ideas to a broader public. In all spheres of life computer graphics are increasingly influential - by some estimates computed visions constitute the "dominant medium of thought" (Gooding 2008:1). Archaeological computer graphics in turn build on a long tradition of physical model building for the development of understanding, and representation of conclusions. Indeed such physical models are now finding a renewed significance as the scanned basis for digital simulation (Earl et al 2009; Guidi et al 2005). Critiques and understandings of digital representations of space also build on the tradition of painted panoramas (Grau 1999). Gooding (2008:8) has demonstrated the ways in which two-dimensional images in a variety of scientific contexts are used to form and evaluate evolving, internal three-dimensional models. Similarly Forte identifies the role of three-dimensional models as mediators between alternative spatial systems what he terms "multi-commensurability" (Forte 2008: 28). 
Computer graphics are based on three-dimensional digital objects constructed from a network of points. These points are generally connected together to form a mesh of triangular or quadrilateral facets interpreted by the computer as physical objects. In turn these facets are made to behave in ways similar to the real environment, taking on properties such as colour, reflectivity, transparency and influencing their surrounding digital environment by obscuring other objects, bouncing light and casting shadows. These multi-coloured, complex meshes exist within a set of Cartesian co-ordinate systems generally viewed either in conventional projections such as the orthographic and the isometric, through virtual cameras, or through attempts to mimic human vision.

This paper examines such computer graphic simulations, and formal and informal uses of them as a means to model archaeological data and archaeological thinking. The paper's main contribution is its focus on the perspective of the model-maker rather than upon the consumer, through an understanding of models both as 'constructions of past lifeways' and as 'thinking spaces'. These concepts are explored through two case studies. The first employs models as modes for re-engaging with archaeological material, where the perception of modelled past environments is taken analogically to inform an understanding of the past as imagined. Questions such as the relationship between digital model experience and a former, unattainable past reality are introduced, alongside the potentials and dangers of a model that may become perceptually indistinguishable from reality. In the second case study, models provide new forms of space within which to build interpretations: they are active vessels for interpretation and debate in the present. The case study considers the relationship between presence and the development of interpretation, and considers 
the agency of digital objects and the possibilities of virtual collaboration. Model building is explored biographically.

\section{Computer Graphic Models in Archaeology}

Use of computer graphic modelling tools in archaeology to replicate ways both of seeing (such as the photographic) and material properties (solidity, colour, texture) has a long history. Huggett's discussion of technological fetishism (2004) and Gidlow (2002) both note the limited critique of computational archaeology. The computer model enables extremely complex components to be examined concurrently, but also encourages abdication of authority to the simulation (Huggett 2004). More recent discussions of 'virtual archaeology' focus on its continued theoretical naivety and oversimplification. Forte launches a "manifesto" for replacing "visual" and "representational" virtual archaeologies by "immersive" and "interconnected" cyberarchaeology (2010: 13). His focus is on engagement with information - with representation implying a fixed, didactic modelling of the past, and cyber-archaeology offering a more involved simulation tied to the processes and data available. The critique of reconstruction as a term extends to the 1940s, with Taylor (in Clarke 2010: 67) preferring 'constructions' as a means to indicate the active role of the modeller in the present, in contrast to a time-travelling process recreating a copy of the past. The community of practice has similarly been critiqued - it is undertaken by a "coterie of technophiles" (Bateman 2004).

Gillings (1999, 2000, 2004) identified the complexities and potentials of archaeological applications of sensory simulation technologies. He introduced Idhe (1993) in the context of the objectification of the simulated past and more recently the role of technological modes of visualization on interpretation (Idhe 2005; see also Gooding 2008: 17). He also considered Benjamin's (1970) discussion of the aura of 
the real, and Baudrillard (1994) in terms of the relation between simulation and reality. My own work explored below focusses on the active role of digital objects and their transformation as situated, historical practice.

Archaeological visualisation technologies parallels the use of visual metaphors in the field and laboratory. The excavated section through the ground is rendered on cleaned, two-dimensional orthogonal axes. Computer modelling similarly divides up the virtual three-dimensional world into two-dimensional representations such as front or side view, employing conventional forms such as scales and parallel edges which in turn influence modelling processes (King 1999). It provides Euclidian windows onto modelled space (Flynn 2007: 350), which limit forms of engagement. By comparison, virtual cameras mimic the optic properties of physical cameras in order to stimulate the same perceptual responses associated with photographs and film. They draw on familiar forms of archaeological photography in order better to convey the form of material remains, and stimulate emotional responses associated with photographic and cinematographic tropes (Earl 2006).

A final form of visual engagement comes through attempts to mimic human vision. Rather than photographic artefacts such as lens flair, chromatic aberration or depthof-field, such visual representations modify field-of-view, perspective and depth perception, and lighting accommodation. The modelling environment becomes a new, active place within which to practice archaeology, with the virtual camera providing a means to snapshot this interaction. Kenderdine has argued that such "perspectival devices have become so integral to our visual understanding that they affect our seeing” (2007a: 315), with ubiquitous linear perspective overpowering other expressions of space and form. 
Computer graphic modelling in archaeology ranges from qualitative assessment of spatial experience to quantitative simulations. The latter has appropriated formal analytical tools from architecture. Thus, structural modelling may test the physical stability of hypothesised structures whilst lighting analysis maps patterns and intensities of light and shade in models. Functional appraisals are then made, on the basis of ethnographic studies or architectural standards, relating degree and type of illumination or structural stability to practice. Such engineering and lighting principles are employed in order to provide what Johnson has termed the "network of resistance" (1999) to the models. For example, a study of Thule whalebone architecture showed that the artificial illumination available in these structures meant that most activities must have taken place outdoors or seasonally (Dawson et al 2007). The simulated light levels would make fine motor operations such as sewing difficult. My work has considered natural and artificial illumination in spaces such as a Minoan cemetery (Papadopoulos and Earl 2009) and the Basilica Portuense (Figure 1). The former explored the pattern of light and shade at different times and the physical contraints posed by low lighting levels. The latter examined the partitioning of the Basilica through lighting, and the extent to which this might be considered part of a conscious design process. Such studies have necessarily considered the role of cultural factors on behaviour with respect to available lighting. Lighting analyses commonly characterise a space via contemporary metrics, but although we are used to performing tasks such as sewing under good lighting conditions such activities can equally be performed with little or indeed no illumination. 


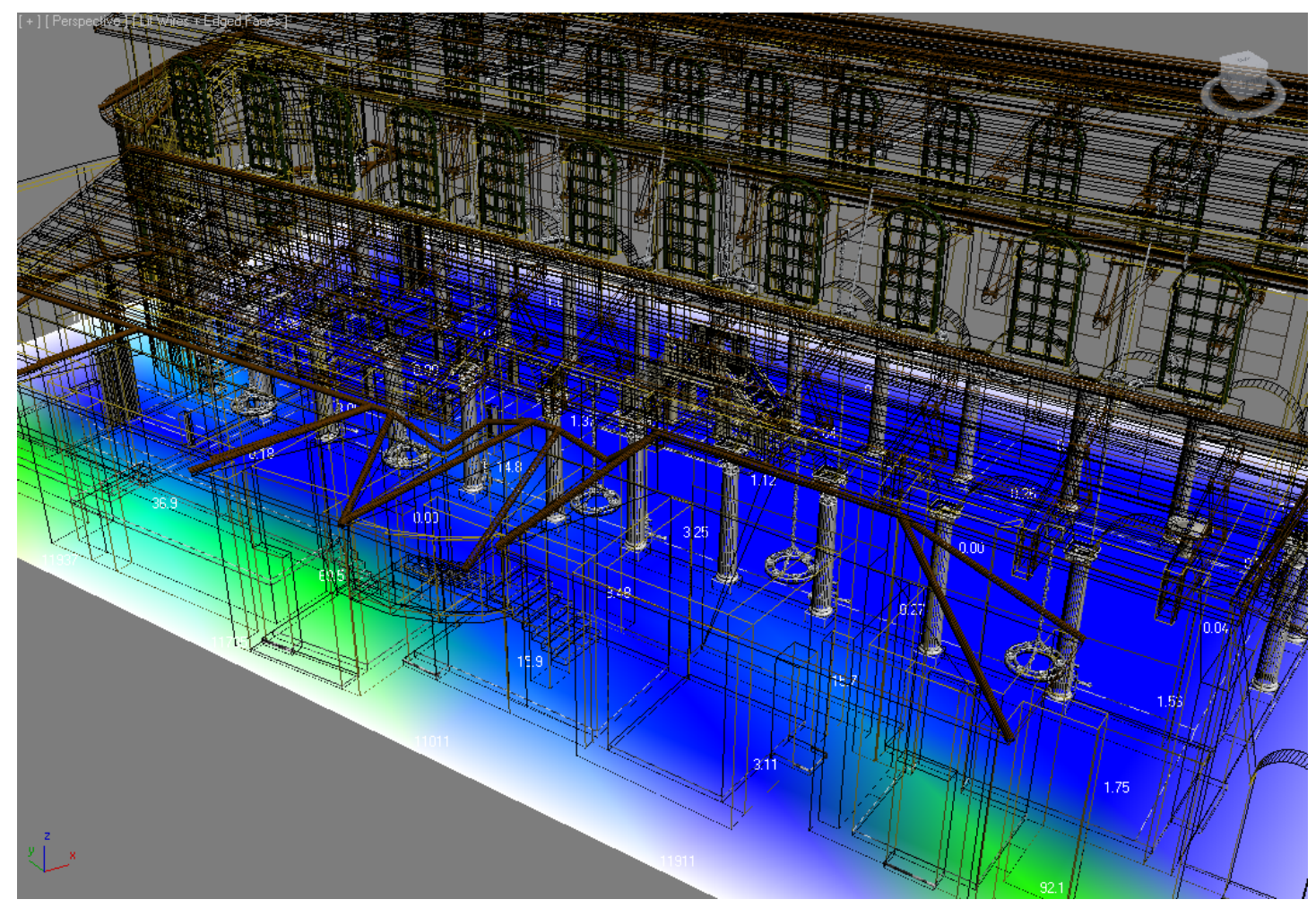

Figure 1: Lighting Analysis Showing Light Reflectance from the Floor of the Basilica Portuense (Konstantinos Papadopoulos ACRG 2011)

Visual interconnectivity may also be analysed, with approaches such as texture viewsheds (Earl 2005), visual 3D (Engel and Döllner 2009), access and visibility graph analysis (Clark 2007) defining quantitative summaries of space and allowing for metric comparisons. Similarly acoustic simulation and analysis provide qualitative and formal mechanisms for analysing the sound of simulated spaces (Watson 2006). These methods provide the means to listen to sounds as if they had been made in a given environment, and to analyse the propagation of sound in comparator environments. Increasingly this forms part of multi-modal approaches which attempt to characterise and experience the breadth of spatial experience (Chalmers and Zányi 2009). In turn concepts such as liminality, enclosure, encounter and circulation common in vision research (Higuchi 1983) may be extended to multi-modal metrics and contrasted to qualitative appraisals of modelled environments. Eye-tracking may be employed to bridge this gap by mapping visual interaction with simulated and real 
spaces in specified contexts, and potentially as a proxy to acoustic experiences (Schleicher et al 2010) in simulated archaeological environments.

\section{Case Study One - Model Building for Construction of Past Lifeways}

\section{Herculaneum}

The site of Herculaneum in Italy was buried by the same eruption of Mount Vesuvius that buried nearby Pompeii in AD79. Working as a collaborative team including colleagues from the Herculaneum Conservation Project and the University of Warwick I am currently exploring the possibilities for computational methods to record and represent sensory aspects of Herculaneum as I believe they were just prior to the eruption (Happa et al 2009a). Currently, I am particularly interested in a Roman statue thought to date from the first century BC that was found buried in the Basilica Noniana near to Herculaneum's still-buried forum. The statue, interpreted by some as of the Sciarra wounded Amazon type, has rich traces of its original pigment and was recovered from a building about which much is known (Guidobaldi 2006).

We have undertaken intricate recording and digital reconstitution of the damaged surface and its pigments, in order to place the statue in a constructed digital counterpart to its hypothesised original physical context at Herculaneum and to examine its visual properties in context (Beale et al 2010; Earl et al 2009). Such statues were commonly adorned with flowers and draped in fabric, supplemented by metal and precious artefacts, and might even have been regularly repainted and modified. These issues, and the fact that the surviving pigment was potentially modified by burial within the pyroclastic flow, means that physical reconstruction of the statue is impractical. Whilst an art historian may faithfully reconstruct Roman pigment - as with the exemplary Gods in Colour exhibition - this process can be 
repeated only a few times (Brinkmann and Wünsche 2007) and cannot realistically extend to accurate recreation of buildings. Cost and time prohibit the reconstruction from exploring the variability inherent in archaeological interpretation. Computer modelling enables infinite experimentation, within boundaries set by the physical characteristics of the surviving data and knowledge of painting processes. This is no simple feat, as accurate surface simulation (as opposed to the creation of visually appealing digital artworks) is extremely computationally intensive and requires a great deal of surface data.

In this context accuracy takes on a multiplicity of meanings. First, can one be accurate to the material recovered - to the surveyed lines and photographed curves that constitute the Basilica and the statue? Second, can the changing nature of archaeological and art historical interpretations of these data be conveyed and explored? Third, for our purposes of engagement, can we take the simulation of such theoretical and physical factors to be realistic?

\section{Physical Realism and Predictive Rendering}

Physical realism in archaeological modelling has had only limited attention (Chalmers 2002; Chalmers et al 2007; Devlin and Chalmers 2001; Devlin et al 2002; Gonalves et al 2008; Happa et al 2009b). In particular predictive rendering, which distinguishes approaches that accurately simulate physical interactions between light, surfaces and volumes (Weidlich and Wilkie 2008) from simulating the appearance of realism (photorealistic rendering), is poorly explored in cultural heritage. In part this is due to the novelty of its underlying methods.

Realism is a slippery term. Lévy has effectively dismissed the separation between digital simulation of archaeological experience and physical embodied practice (1998). The real is defined in these terms by what it is possible to do. In Bazin's 
(1960) sense the photographic inputs to a computer graphic simulation are indexically real: they accurately capture visual stimuli (in terms of representative fidelity). One might usefully contrast this to questions of verisimilitude and mimesis. Here the archaeological graphic simulations carry with them a sense of the familiar real world that encourages engagement but which need not replicate physical reality. Taken to its extreme in the Electronic Baroque (Klein 2004 in Kenderdine 2007a), where we are taken on digital journeys that are compelling but self-conscious, this realism drags us into the narrative whilst freeing us from the constraints of the real world. The photographic snapshot of the virtual world described above can therefore be critiqued in terms of photorealist collage:

"In [modelling] a snapshot of three-dimensional space is defined on the basis of discrete slices through reality, each with its own history. The photorealist allows physics and the lens to define patterns of light, shade and colour, and then creates art from them through choice and, possibly, collage... Rather than implying a physical duplication of a past reality through computation, or artificially simulating a world as it is imagined to have appeared, instead the archaeologist takes physically accurate vignettes and constructs from them an archaeological narrative, through rich interpretation. With the Amazon whole visual universes of discourse can be constructed physically-accurately in potentia, and then virtually photographed as needed." (Earl 2009)

The physical realism of predictive rendering evokes the real world, through the perceptual realism (Prince 1996) implied by the photographic form. This enables us to bridge the divide between our experienced world of the present and our perceptually consistent experience of an imagined, photographed past. Thus, the statue head from Herculaneum is placed in a context that, whilst having a basis in the indexical reality 
of photographs of mosaics and wall plaster, is at once wholly artificial and wholly perceptually real. Forte (2008: 30) has identified the benefits of such perceptual realism in terms of qualities or "affordances" (Gibson 1977) and of its evocative qualities. The latter is also at the heart of debates concerning new photographic representations of archaeological practice (Hamilakis 2009), where fragments of the past, expressed through fragmentary representations in film, on paper, screen or otherwise, may evoke more completely a sense of past. The role that predictive rendering plays in this relationship is again to define the network of resistance, such that perceptual realism merges with an indexical appreciation of space. The predictive render of the statue's eye pigment allows for light interacting with colour and substrate and evokes rich artistic practice. Similarly the shadows cast across the statue's face are a product of the physical laws governing photographic capture (including lens, exposure and resolution) and contextualized in a familiar, perceptually real scenario (the sunlight and shade of the Bay of Naples).

Such a focus on realism is not without problems. Most obviously the constructed nature of the simulation might not be appreciated by the viewer. It is an academic responsibility to indicate the authenticity of our representations, in terms of the underlying information and the interpretative process. Many technological and stylistic methods have been proposed in this context, including varying uses of transparency, digitally signposting particular elements and degrading the visual fidelity of the areas that are considered less certain. Such attempts whilst useful in some contexts to represent archaeological process are not necessary components of digital representations and fail to represent the complexity and ambiguities of interpretative practices, and to limit uncertainties to those represented. Thus, using a specific stylistic approach (such as those proposed by Eiteljorg 2000 and Forte 2000; 
see also Frischer 2008) might show that particular parts of a Herculaneum mosaic are conjectural, but in turn overlook the greater uncertainty in the stylistic interpretation of the mosaic itself.

Just as photorealist art mixes construction and stimulation by expressing truthlikeness but acknowledging its underlying artificiality, so graphic modelling can represent the past without stylistic indications of uncertainties and arguments, providing the context make clear that these exist (Figure 2). It is because the computer can create such artificial distinctions that they have been used (Earl 2006: 199; Clarke 2010: 70). Clearly such models whether digital or not require detailed critique in terms of the history, grammar and implications of the representations produced (e.g. Moser 1998; 2001). But this does not in itself require them to be less compelling visual narratives. but does not need to be restrained. It is perhaps for this reason that archaeological computer graphic models so seldom depict humans. It is not to sanitise the past but rather to remove the elements that more than anything show digital models for the constructions that they are (Mori 1970).

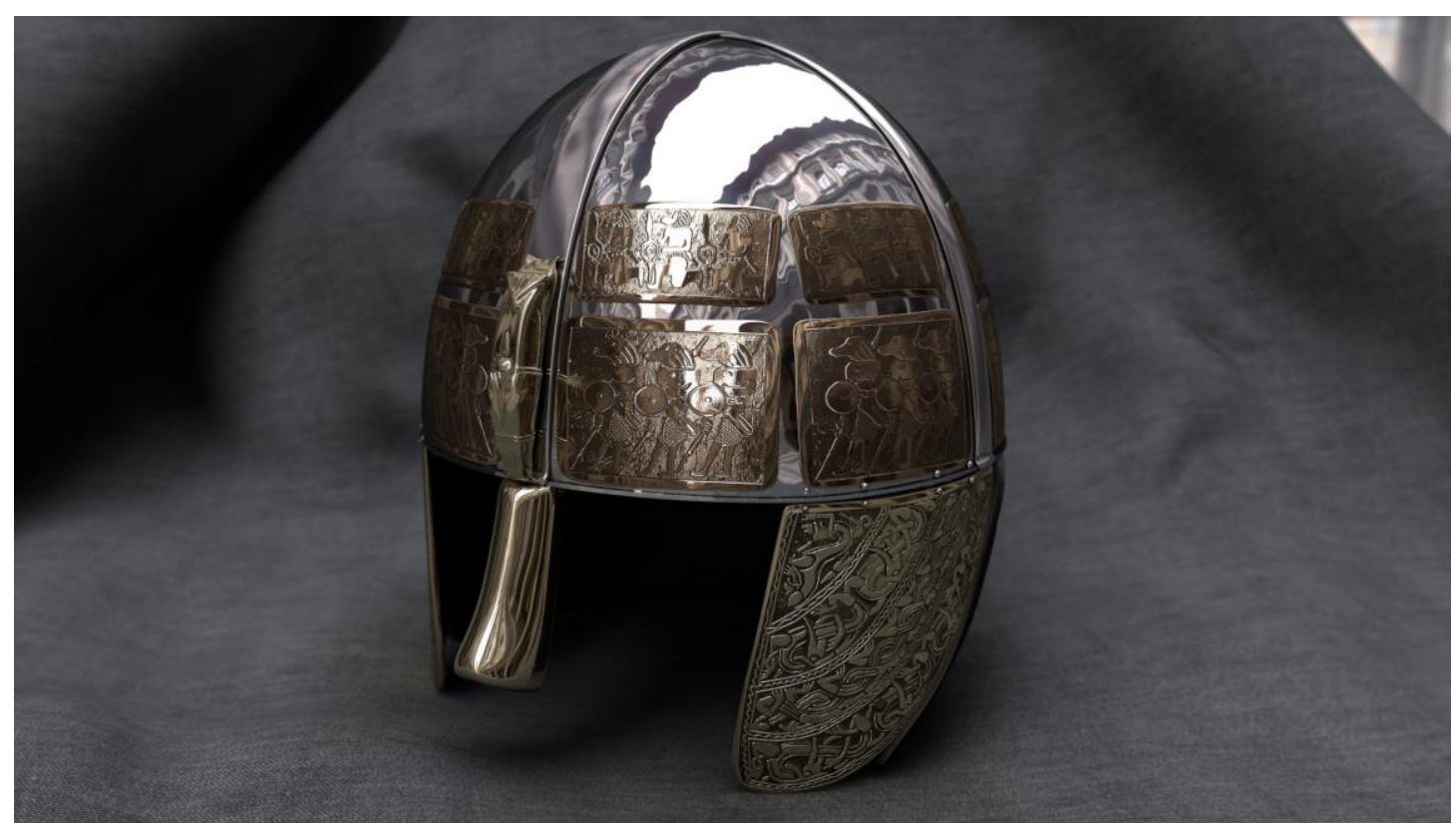


Figure 2: Simulation of Anglo-Saxon Helmet on the Basis of Small Fragments from the Staffordshire Hoard (Grant Cox ACRG 2011)

However, increasingly photorealism has been critiqued as a limiting factor in the ability of those models to communicate and to build hypotheses (Gooding 2008), particularly if representative models can be at their most powerful as simplifications (Morgan and Morrison 1999:27). Barceló sees visual models as means to represent empirical phenomena alone - as such they do not extend beyond captured archaeological data. He suggests that the only impact of increasing the detail of more exploratory models (equivalent to "nice' reconstruction using watercolours") is "the generation of an even more fastidious investigative attitude on the part of the observer" (2007: 453). However, it is here perhaps that the true power of predictive rendering approach lies - the physical components of the simulation can be isolated in order to stimulate interpretation of discrete perceptual components such as light, shade and colour, and also emotional factors such as a sense of enclosure, exposure, or isolation.

Physically real representations do not require a uniformitarian understanding of the impact of space on practice in order to approach past lifeways. At Herculaneum the literary sources alone identify a Roman past that whilst eliciting many apparent similarities was very different from our own. However there remains sufficient cultural and perceptual continuity for the relational analogies made possible by graphical simulation to be valid. This continuity will vary for differing material culture and for by the interpretative context in which it is used, but the constructed, modelled past founded on physical properties provides a framework to see environments that have now disappeared. The past is not being seen through Roman eyes, but the past is being seen in some sense. In turn, since we are interested not only in how the statue would appear were the Basilica Noniana standing now and the 
statue was as originally created, but more than that we are analogically seeking through theory to follow a broken trail of experience to Roman encounters with the statue.

Such an approach has had prominent critiques from within archaeological theory, most notably Thomas (2004) who dismissed attempts to add a human dimension to computational practice. Similarly Lock (2003) has warned against equating digital and real experience, or at least in undertaking analyses of experience in these two realms using similar methods and theoretical frameworks. However the computational research described examines exactly the same questions of Roman style, intentional position and juxtaposition that other archaeological researchers examine through scale drawings and photographs. Roman art, architecture and archaeological literature refer to issues such as the appearance of statues in context, the relationship between intended location and design and execution of a statue, the experience of space and place, the physical and social patina of Roman spaces, and the place of statues as socially situated objects rather than as idealised forms on display. And yet such work is largely premised on a museum catalogue or display, or a visit to an archaeological site, or to an internal, imagined landscape of Roman objects in space. It is inevitably based on fragmentary artefacts and architecture, frequently out of physical context. Thus, whilst research has defined Roman 'rooms' on the basis of social action, decoration, light as much as on architecture, this has rarely considered the multisensory context. Similarly, movement around such spaces is a key mechanism for interpretation, whether explicit through phenomenological appraisal or implicit in research history, and yet movement on an archaeological site is mediated by the extent of preservation and the rules of access, rather than by the original structure of the space. By using models of objects and spaces we confront these limitations, 
accepting a relationship between the modelled space and some imagined Roman past. In turn we may employ the formal methods such as lighting analysis outlined above to frame such experiential, virtual phenomenological methods.

\section{Case Study Two - Model as Thinking Space}

The Neolithic town of Çatalhöyük in Turkey was inhabited 9000 years ago. Modelling work here is providing new digital spaces to think inside, and in particular driven by a need to visualise wall paintings in context and under varying conditions (Figure 3). The outputs of the modelling work whilst appealing are less significant than the spatial processes by which they are formed. The models are used as a means of visual stimulation, as a conflation and reasoned extrapolation of archaeological data designed to stimulate thought. This focus on experience of contemporary space, whether physical or virtual, is as explicitly phenomenological as the discussion of past lifeways above. It draws equally from socially constructed and cognitive models, within which the interpretations building from experience in the present are differently relevant to discussions of past experience and action. Navigation and interaction within digital immersive environments provide new bodily engagements with real and imagined archaeological environments (Champion 2010; Kenderdine 2010). Forte's "cyber-archaeology" is thus a bridge between objective "processual" and subjective "post-processual" archaeologies, within which new spaces for interpretation are formed in part autopoietically (2010:10; Zubrow 2010:2). In this way the model can expose alternative ontologies of space (van der Elst 2010). 


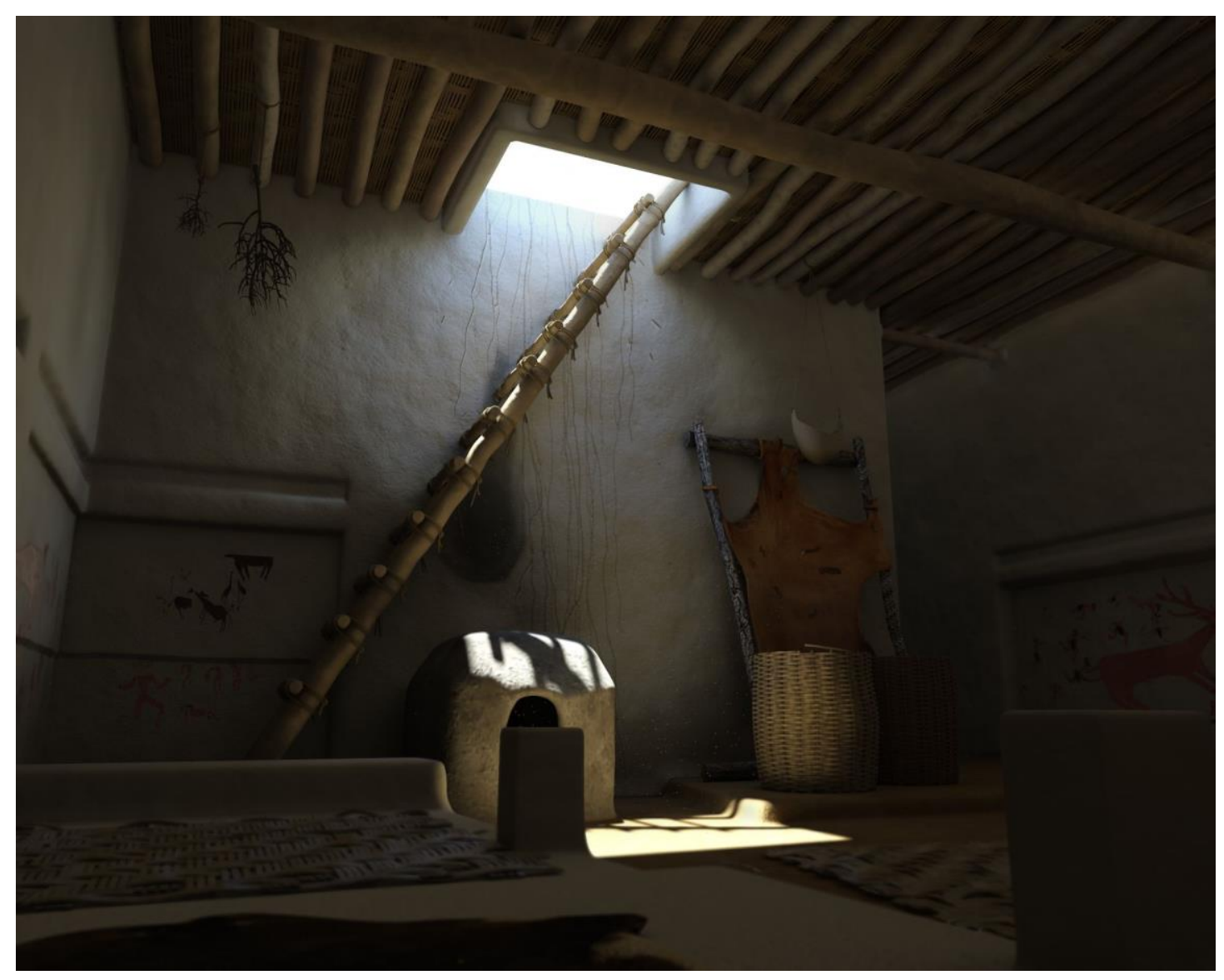

Figure 3: Simulation of Çatalhöyük Interior (Grant Cox ACRG 2011)

A sense that the viewer is physically present within a constructed digital environments is a key factor in embodied digital experience. The Performing Presence Project (Kaye et al. 2010) examined this relationship in virtual and mixed reality environments such as Collaborative Virtual Environments (CVEs) where the viewers might interact with each other, with virtual humans, and in virtual space. In the project narrative devices, the performance of real and simulated agents and the mixed reality merging of actual and virtual components provoked a deep sense of engagement in a world that offered little visual stimulation (Kenderdine 2007b). The virtual environment experienced was simple with no attempt at photorealism, and at times was deliberately seen to "break down" - to expose its artifice. This work supported the hypothesis that overly detailed renderings could in fact reduce the sense of presence, if presented outside of narrative (Flynn 2007: 353). In turn it suggests 
that the modelling interfaces used to generate environments captured in Figure 3 could be equally powerful as emotive tools.

The engagement in the Presence Project was constructed through narrative practice. The real and virtual actors' roles affected the resulting experience, with the anticipation of the experience and the discussion afterwards being as much core to it as the brief period spent immersed in the virtual world. Here the participants could move from being observers (literally peering through the veil dividing the real world from the virtual performance space to see others' virtual experiences unfolding), to mediators (passing real objects into a simulated world), to participants, to critics with each orientation redefining the experience of the model. The significance of presence has been explored in depth by game designers (Pinchbeck and Stevens 2005; Flynn 2007: 359ff). Here perceptual realism and a storied environment interact with the user, effectively creating a pact where the user conforms to game constraints in return for engagement in the game. Archaeological spaces require an identical reciprocity, but the incorporation of narratives, exploration and interaction remains rare (Champion 2010: 85). It was for this reason that my research in Egypt (Earl 2004a) was characterized by rich textual narratives, providing a description of a visit to the simulated town, which complemented visual simulations, building in turn on the narrative archaeologies of Joyce (2002) and others. Archaeological worlds also require the rich multimedia experimentation described by Zelinski as "dramaturgies of difference" (in Kenderdine 2010:47) in order to make clear their constructed nature and to encourage critique.

Modellers spend months building a familiarity with archaeological data that is interpretatively rich, but is largely virtual. This is a craft activity. Where possible they engage with the physical materiality of the past in order to build connections between 
the models and their reality. Indeed I encourage the construction of models on site, bound in to the processes of excavation and recording. In this way the models on the screen build up a tangible narratives of practice that is personal but shared; an externalised vision. Whilst the modeller may not be goal-driven in the sense of a game's requirements, the very real imperatives of model design provide a history and process to engagements with the digital archaeological world. This is a dwelling process (Cripps et al 2006) whereby the archaeologists dwells in an archaeological environment that they are simultaneously creating, transforming and destroying. Such an engagement with the model is different from one mediated by a still or animated representation of the same data.

The modelling process can lead to surprises, to unexpected consequences and adjacencies, just as archaeological sketching creates archaeological interpretations. However, it is seldom clear to what degree the computer graphic is an instantiation of an internal model, or if in fact it is the process that defines both the model and the understanding of the physical object or place. Procedural modelling tools such as CityEngine and Grasshopper may offer further insight into modelling process. They generate models according to rules or 'shape grammars' (Stiny 1975) within a given parameter space (Müller et al 2006; 2007). As a consequence they enable sensitivity analyses by producing multiple versions that express the parameter space and make explicit the governing assumptions in a model. For example, in on-going work on the Navalia at Portus where the postulated building and its underlying data have been reinterpreted in multiple stages we have produced many alternative simulations of the building automatically, evaluated the outputs, and then generated final photorealistic snapshots to express our conclusions and to stimulate new interpretations. 
Modelling tools become digital prostheses and through repeated experience the prosthesis becomes assimilated into bodily experience. These tools may in turn be accompanied by "cyber-maps" which visually express their underlying data and interpretative processes (Forte in Forte 2010; Galeazzi et al 2010), enabling enhanced interaction with vast bodies of archaeological data (Earl et al in press; Levy et al 2010). Increasingly the tools include multi-modal devices which stimulate a range of senses, such as acoustic simulation, smell or haptics (Magnenat-Thalmann et al 2007). As such they allow for a broader interaction of bodies and data in space, that are together crucial to their interpretation (Forte in Frischer 2008: 26; Kirsh 2010; Milekic 2007; Hamilakis et al 2002). These modelling environments clearly are places: socially defined, personal, historical "spatially visualised, activity-based or hermeneutic environments" (Champion and Dave 2007: 333). A shared sense of place comes through manipulation of digital objects as tokens, rather than through indexical realism (alone), and archaeological modelling environments create this: personal spaces, shared environments of debate, revised areas with history. Models thus hold the patina of multiple interactions and transformations with the modelled world.

\section{Digital thinking at Catalhöyük}

At Çatalhöyük and elsewhere we are building spaces that have very considerable perceptual realism but we do not conceptualise them as a recreation of past reality. Rather they provide an ever changing set of places for visualising the information available to us. In particular they are enabling us to take the fragmentary archive of the earlier 1960s excavation of the site and combine it with the modern excavation results in order to produce sensory experiences. Predictive rendering supports the use and critique of these simulations as if they were part of the same habitual, material culture practice of archaeologists in the real world. The virtual object moves from 
representing a real or imagined physical counterpart and instead is understood to be real. First, the artefact is a product of interactions in physical and digital space - it is modelled, developed, destroyed and remade - and second it takes on the aura of past agency. Such agency is empowered by an understanding of the digital artefact as “digital historical objects... in their own right" (Cameron 2007: 54). Indeed Cameron argues that the aura of the virtual object is an enhanced version of any object it might be seen to replicate - it has increased cultural capital through the choice and effort involved in replication (2007: 57). To the modeller the object is at once old and new, whilst to the observer and user it might be conceptualized solely in terms of a hypothetical ancient biography (Kopytoff 1986). Thus, the stretched skin in the Çatalhöyük simulation carries with it a sense of past processes of manufacture and implied future use, made explicit by the skin used as a floor covering elsewhere in the simulated room (Figure 3).

Such multiple agency fits within archaeological frameworks that appreciate the multiplicity of meaning associated with objects. The model explicitly combines rather than separates the object from the actor. It demonstrates that there are in fact two model types at play - the model of the production of the simulation (defined perhaps as the model of disciplinary practice in a given context, and including computational tool use) and the simulations produced. It also fits with a consideration of the images produced as snapshots - implying a moment caught from dynamic life off-camera (Barthes 1993), rather than a staged portrait to be consumed. In this sense the simulations produced are non-representational in focus - they serve to conjure an understanding of practice rather than defining views that might result from such practice. In our work on the Shrine of the Hunters at Çatalhöyük this is particularly compelling - the simulations provide a means to visually engage with the lost wall 
paintings in the present. Contrary to this active conceptualisation of modelling there is a tendency to view reconstructions as a single image when complete, and as individual components when being assembled. There is little sense of the interaction of components. Those interactions that do exist are characterised as physical (objects being placed on top of one another, finite element analysis, interaction between a light source and object materials) rather than social.

The final significance of the modelling of Çatalhöyük is in terms of collaboration. This is in the sense identified by Forte (2010) in terms of collaborative archaeological environments for negotiating interpretation, but also as locales made significant not only by their impacts on the archaeological interpretation but also on the participants in the modelling and the active observers and critics. Returning to patina, we must seek methods by which the digital model might take on some element of this history, and explore the agency of the modellers, those surrounding the modelling process, and the components of the model. Some of this is addressed by the increasingly varied documentation of modelling process - the blog, narrative, metadata, semantic annotation (Attene et al. 2009) - but its depth still remains to be explored.

\section{Conclusions}

In his introduction to Beyond Illustration Frischer cites five benefits to visualization outlined by Ware:

- It may facilitate the cognition of large amounts of data

- It can promote the perception of unanticipated emergent properties

- It sometimes highlights problems in data quality

- It makes clear the relationship of large-and small-scale features

- It helps us to formulate hypotheses (2004) 
The research outlined above demonstrates examples of each of these in the context of computer graphic simulation. At Herculaneum the models enable rapid assimilation of large and complex datasets and demonstrated problematic and surprising information. In the lighting studies of the Basilica Portuense the models encourage the perception of previously obscured components, and create new ways of seeing the site. At Çatalhöyük the models articulate issues of scale, providing at once holistic and focused ways in to the Shrine of the Hunters, both in terms of the perceived simulation and of its construction through research and model building. Finally, at Herculaneum the models continue to assist in the formulation of new hypotheses. In Goodings' terms the Çatalhöyük models offer a simplified abstraction that is more readily understood, whilst the Herculaneum models start by offering an initial appraisal of the available data, are gradually becoming the locus for discussion, and will form the basis of dissemination and re-evaluation (2008: 3). Together modelling has been seen to be an active process, investing digital and physical participants with agency, which accumulate an interpretative valuable patina.

Archaeology continues to battle with its position in terms of model building and critique. CP Snow's 1959 Rede lecture (1960) still has resonance in the structures of archaeology where archaeological science, archaeometry, archaeology and anthropology dance slowly around and in and out of one another. The model as testable, absolute metric for past behaviour is increasingly restricted to formal models of isotopes, osteological traits or ceramic inclusions. But beyond these archaeology lacks certainty. It is at once a discipline familiar with and embracing of diversity and community. The way we employ models, and thus theorise our computational expressions of the world, is contextual. We cannot devise a single modelling approach. Still, commonly the output - the still image, the animation, even the 
interactive game world - holds far less value for the archaeologist than carving out the model with the crude modelling tools available, constrained to Cartesian worlds but alive with creative potential. Archaeology in each of the examples I have introduced is an intensely political and personal activity. The models therefore must ebb and flow with cultural sensitivities and be prepared to be shattered over and over again.

\section{References}

Attene, M., Robbiano, F., Spagnuolo, M. and Falcidieno, B. 2009. Characterization of 3D shape parts for semantic annotation. In Computer-Aided Design 41 (10) p. 756763

Barceló, J. 2010. From Computable Archaeology to Computational Intelligence. New Prospects for Archaeological Reasoning. In Forte, M. (ed.) Cyber-archaeology. Archaeopress: Oxford

Barceló, J. 2007. Automatic Archaeology. In Cameron, F. and Kenderdine, S. Theorizing Digital Cultural Heritage. London: MIT Press

Barthes, R. 1993. Camera lucida, London: Random House

Bateman, J. 2004. Wearing Juninho's Shirt: Record and Negotiation in Excavation Photographs. In S. Moser and S. Smiles (Eds) Envisioning the past. Oxford: Blackwell

Baudrillard, J. 1994. Simulacra and Simulation. Ann Arbor: University of Michigan Press.

Bazin, A. 1960. The Ontology of the Photographic Image. Translated by Hugh Gray. Film Quarterly, Vol. 13, No. 4. (Summer, 1960), pp. 4-9. 
Beale, G., Earl, G.P., Chalmers, A., Happa, J. and Williams, M. 2010. Polychromy, Digital Simulation and an Amazon from Herculaneum, In: A. Moore, A., G. Taylor, E. Harris, P. Girdwood, L. Shipley (eds), Conference Proceedings, TRAC 2009.

Benjamin, W. 1970. The work of art in the age of mechanical reproduction. London: Jonathon Cape

Brinkmann, V. and Wünsche, R. (eds) 2007. Gods in Color: Painted Sculpture of Classical Antiquity. Stiftung Archäologie and Staatliche Antikensammlungen und Glyptothek, Munich

Cameron, F. 2007. Beyond the Cult of the Replicant. In Cameron, F. and Kenderdine, S. Theorizing Digital Cultural Heritage. London: MIT Press

Chalmers, A. 2002. Very Realistic Graphics for Visualising Archaeological Site Reconstructions, In: Conference Proceedings, 18th spring conference on Computer graphics, ACM Press, New York, 7-12.

Chalmers, A and Zányi, E. 2009. Real Virtuality: Emerging Technology for Virtually Recreating Reality, in: Becta, http://www.becta.org.uk.

Chalmers, A.G., Debattista, K., Mastoropoulou, G. and dos Santos, LP. 2007. There reality: Selective rendering in high fidelity virtual environments". International Journal of Virtual Reality, vol 6, no 1.

Champion, E. 2010. Wayfinding across space, time, and society. In Forte, M. (ed.) Cyber-archaeology. Archaeopress: Oxford

Champion, E. and Dave, B. 2007. Dialing Up the Past. In Cameron, F. and Kenderdine, S. Theorizing Digital Cultural Heritage. London: MIT Press 
Clark, D.L. 2007. Viewing the liturgy: A space syntax study of changing visibility and accessibility in the development of the Byzantine church in Jordan .World Archaeology. Vol 39.1. 84-104

Clarke, J. 2010. The Fallacy of Reconstruction. In Forte, M. (ed.) Cyber-archaeology. Archaeopress: Oxford

Cripps, P.J., Earl, G.P. and Wheatley, D.W. 2006. A dwelling place in bits. In, Jorge, Vitor (ed.) Approaching prehistoric and protohistoric architectures of Europe from a dwelling perspective: proceedings of the TAG Session Sheffield, 2005. Porto, Portugal, Associação para o Desenvolvimento da Cooperação em Arqueologia Peninsular. Journal of Iberian Archaeology 8

Dawson, P., Levy, R., Gardner, D. and Walls, M. 2007. Simulating the Behaviour of Light Inside Arctic Dwellings: Implications for Assessing the Role of Vision in Task Performance, in: World Archaeology, 39, 1, 17-35.

Devlin, K. and Chalmers, A. 2001. Realistic Visualisation of the Pompeii Frescoes, in: A. Chalmers and V. Lalioti (eds), Conference Proceedings, 1st international conference on Computer graphics, virtual reality and visualisation, AFRIGRAPH 2001, ACM Press, 43-47.

Devlin, K., Chalmers, A., Brown, D. 2002. Predictive Lighting and Perception in Archaeological Representations, in: Conference Proceedings, UNESCO World Heritage in the Digital Age, 30th Anniversary Digital Congress.

Earl, G.P., Keay, S.J. and Beale, G. In press. Archaeological computing for recording and presentation of Roman Portus. In Keay, S.J. and Paroli, L. (eds) Proceedings of the First Portus Workshop, held at the British School at Rome, March 2008. British School at Rome Monographs 
Earl, G.P. 2009. Physical and Photo-Realism: The Herculaneum Amazon. In Plenary session: Fundamentos teóricos de la Arqueología virtual. Proceedings of Arqueologica 2.0 Seville 2009

Earl, G.P., Gareth Beale, G., Happa, J., Williams, M., Turley, G., Martinez, K., Chalmers, A. 2009. A Repainted Amazon. In Proceedings of the 2009 EVA London Conference

Earl, G.P. 2006. At the edges of the lens: photography, graphical constructions and cinematography. In T.L. Evans (Ed.) Digital Archaeology. London: Routledge

Earl, G., Keay, S. and Beale, G. 2009 Evaluating Gismondi's representation of Portus, the port of imperial Rome. In proceedings Arqueologica 2.0, Seville, Spain. Available from: http://eprints.soton.ac.uk/152953/

Earl, G.P. 2005. Spatial summaries of built archaeological spaces: a technique derived from global light mapping. Proceedings of the 11th International Conference on Virtual Systems and Multimedia, Ghent, Belgium VSMM (2005) Brussels: ENAME

Earl, G.P. 2004a. Desert stories, desert sites: multimedia and the archaeological process in Egypt. Proceedings of the 10th International Conference on Virtual Systems and Multimedia, Gifu, Japan VSMM (2004). 2004.

Earl, G.P. 2004b. Video killed interpretative VR. In S. Moser and S. Smiles (Eds) Envisioning the past. Oxford: Blackwell

Eiteljorg, H. 2000. The Compelling Computer Image - a double-edged sword. In $\begin{array}{llll}\text { Internet } & \text { Archaeology } & 8 & \text { [on-line]: }\end{array}$ http://intarch.ac.uk/journal/issue8/eiteljorg_index.html. 
van der Elst, J. 2010. Exploring cognitive landscapes: toward an understanding of the relationship between space/time conceptualization and cultural material expression. In Forte, M. (ed.) Cyber-archaeology. Archaeopress: Oxford

Engel, Juri and Döllner, Jürgen 2009. Approaches Towards Visual 3D Analysis for Digital Landscapes and Its Applications. Digital Landscape Architecture Proceedings 2009, pp. 33-41

Flynn, B. 2007. The Morphology of Space in Virtual Heritage. In Cameron, F. and Kenderdine, S. Theorizing Digital Cultural Heritage. London: MIT Press

Forte, M. 2010. Introduction to Cyber-Archaeology. In Forte, M. (ed.) Cyberarchaeology. Archaeopress: Oxford

Forte, M. 2008. Virtual Archaeology: Communication in 3D and Ecological Thinking, by Maurizio Forte. In Bernard Frischer and Anastasia Dakouri-Hild (eds) Beyond illustration: $2 \mathrm{~d}$ and $3 \mathrm{~d}$ digital technologies as tools for discovery in archaeology. Archaeopress.

Forte, M. 2000. About virtual archaeology: disorder, cognitive interactions and virtuality. In J. Barceló, M. Forte and D. Sanders (eds) Virtual reality in archaeology, Oxford: BAR International Series

Frischer, B. 2008. Introduction: From Digital Illustration to Digital Heuristics, by Bernard. In Bernard Frischer and Anastasia Dakouri-Hild (eds) Beyond illustration: $2 \mathrm{~d}$ and $3 \mathrm{~d}$ digital technologies as tools for discovery in archaeology. Archaeopress

Galeazzi, F., Di Giuseppantonio Di Franco, P. and Dell'Unto, N. 2010. 3D Cybermaps of Western Han Mural Tombs. In Forte, M. (ed.) Cyber-archaeology. Archaeopress: Oxford 
Gibson, J.J. 1977. The theory of affordances. Perceiving, acting and knowing: toward an ecological psychology, 67-82

Gidlow, J. 2002, Rock art and "bubble worlds", in Wheatley, D., EARL, G. and Poppy, S. (eds) Contemporary Themes in Archaeological Computing, University of Southampton Department of Archaeology, Monograph 3, Oxford, Oxbow Books, 1621.

Gillings, M. 2004. The Real, the Virtually Real, and the Hyperreal: The Role of VR in Archaeology. . In S. Moser and S. Smiles (Eds) Envisioning the past. Oxford: Blackwell

Gillings, M. 2000. 'Plans, elevations and virtual worlds: the development of techniques for the routine construction of hyperreal simulations', in J. Barceló, M. Forte and D. Sanders (eds) Virtual reality in archaeology, Oxford: BAR International Series

Gillings, M. 1999. 'Engaging place: a framework for the integration and realisation of virtual-reality approaches in archaeology', in L. Dingwall, S. Exon, V. Gaffney, S. Laflin and M. van Leusen (eds) Computer applications and quantitative methods in archaeology 97, Oxford: Archaeopress

Gonalves, A., Magalhes L., Moura J. and Chalmers A. (2008): Accurate Modelling of Roman Lamps in Conimbriga using High Dynamic Range, in Proceedings of VAST 2008, Eurographics, 2008

Gooding, D.C. 2008 Envisioning Explanation: The Art in Science, by David C. Gooding. In Frischer and Dakouri-Hild (eds) Beyond illustration: 2d and 3d digital technologies as tools for discovery in archaeology. Archaeopress 
Guidi, G., B. FRISCHER, ET AL. (2005) "Virtualizing Ancient Rome: 3D Acquisition and Modeling of a Large Plaster-of-Paris Model of Imperial Rome,”, in Beraldin, J.-A., El-Hakim, S.F., Gruen, A., Walton, J.S. (eds) Videometrics VIII 1820 January 2005, San Jose, California, USA, SPIE, vol. 5665, pp. 119-133.

Guidobaldi, M. P. (2006): Una testa di amazzone dipinta, in Forma Urbis, 11.4, 4-7

Hamilakis, Y. 2009. Indigenous Hellenisms/indigenous modernities: Classical antiquity, materiality, and modern Greek society. In G. Boys-Stones, B. Graziosi and Ph. Vasunia (eds), The Oxford Handbook of Hellenic Studies. Oxford: OUP, pp. 1931.

Hamilakis, Y., Pluciennik, M. and Tarlow, S. 2002. Thinking through the body: archaeologies of corporeality. New York: Kluwer Academic

Happa, J., Williams, M., Turley, G., Earl, G. P., Dubla, P., Beale, G., Gibbons, G., Debattista, K., Chalmers, A. 2009a. Virtual relighting of a roman statue head from Herculaneum: a case study. In AFRIGRAPH '09: Proceedings of the 6th International Conference on Computer Graphics, Virtual Reality, Visualisation and Interaction in Africa (2009).

Happa, J. et al. 2009b. Illuminating the Past - State of the Art, in: K. Debattista, C. Perlingieri, D. Pitzalis, and S. Spina (eds), Conference Proceedings, 10th VAST International Symposium on Virtual Reality, Archaeology and Cultural Heritage 2009.

Magnenat-Thalmann, N., Volino, P., Bonanni, U., Summers, I. R., Bergamasco, M., Salsedo, F., Wolter, F.E. 2007. From physics-based simulation to the touching of textiles: The HAPTEX Project. In The International Journal of Virtual Reality, vol. 6:3, pp.35-44, Sep. 2007 
Higuchi, T. 1983. The Visual and Spatial Structure of Landscapes, MIT Press, Cambridge, Massachusetts

Huggett, J. 2004. Archaeology and the new technological fetishism. Archeologia e Calcolatori, $15,81-92$

Idhe, D. 2005. Material Hermeneutics. Available from: http://traumwerk.stanford.edu:3455/17/746

Idhe, D. 1993. Philosophy of technology : an introduction. New York : Paragon House

Johnson, M.H. 1999. Archaeological Theory: An Introduction. Oxford, Blackwell

Joyce, R. 2002. The languages of archaeology: dialogues, narratives and writing, Oxford: Blackwell

Kaye, N., Giannachi, G., Kaye, J.N. 2010. Performing Presence: Between the Live and the Simulated. Manchester, Manchester University Press

Kenderdine, S. 2010. PLACE-Hampi, Ancient Hampi and Hampi-LIVE - an entanglement of people-things. In Forte, M. (ed.) Cyber-archaeology. Archaeopress: Oxford

Kenderdine, S. 2007a. Speaking in Rama: Panoramic Vision in Cultural Heritage Visualization. In Cameron, F. and Kenderdine, S. Theorizing Digital Cultural Heritage. London: MIT Press

Kenderdine, S. 2007b. Somatic solidarity, magical realism and animating poular gods: place-hampi 'where intensities are felt'. In Banissi, E., Burkhard, R.A., Grinstein, G., Cvek, U., Trutschl, M., Stuart, L., Wyeld, T.G., Andrienko, G, Dykes, J., Jern, M., 
Groth, D. and Ursyn, A. (eds) Proceedings of the 11th European Information Visualization Conference, IV07: 402-8

King, M. 1999. The Tyranny and the Liberation of Three-Space: a Journey by RayTracer. In Digital Creativity 10:4 pp.215-27

Kirsh, D. 2010. Comparing tangible and virtual exploration of archaeological objects.

In Forte, M. (ed.) Cyber-archaeology. Archaeopress: Oxford

Klein, N. 2004. The Vatican to Vegas. The History of Special Effects. New York: The New Press

Kopytoff, I. 1986. The cultural biography of things: commoditization as process. In Appadurai, A. (ed.) The Social life of things: commodities in cultural perspective. Cambridge: Cambridge University Press

Lévy, P. 1998. Becoming Virtual: Reality in the Digital Age, New York: Plenum

Levy, T.E., Petrovic, V., Wypych, T., Gidding, A., Knabb, K., Hernandez, D., Smith, N.G., Schlulz, J.P., Savage, S.H., Kuester, F., Ben-Yosef, E., Buitenhuys, C., Barrett, C.J., Najjar, M., DeFanti, T. 2010. On-Site Digital Archaeology 3.0 and CyberArchaeology: Into the Future of the Past -New Developments, Delivery and the Creation of a Data Avalanche. In Forte, M. (ed.) Cyber-archaeology. Archaeopress: Oxford

Lock, G. 2003. Using computers in archaeology: towards virtual pasts. Routledge, London

Milekic, S. 2007. Towards Tangible Virtualities. In Cameron, F. and Kenderdine, S. Theorizing Digital Cultural Heritage. London: MIT Press 
Morgan, M.S. and Morrison, M. 1999. Models as Mediators: Perspectives on Natural and Social Science. Cambridge: Cambirdge University Press

Mori, M. 1970. The Uncanny Valley. Energy, 7(4), pp. 33-35

Moser, S. 1998. Ancestral images, Stroud: Sutton

Moser, S. 2001. 'Archaeological representation: the visual conventions for constructing knowledge about the past', in I. Hodder (ed.) Archaeological Theory Today, Cambridge: Polity Press

Müller, P., Zeng, G., Wonka, P. and Van Gool, L. 2007. Image-based Procedural Modeling of Facades. In Proceedings of ACM SIGGRAPH 2007 / ACM Transactions on Graphics (TOG), ACM Press, Vol. 26, No. 3, article 85

Müller, P., Vereenooghe, T., Wonka, P., Paap, I., Van Gool, L. 2006. Procedural 3D Reconstruction of Puuc Buildings in Xkipché, in: M. Ioannides, D. Arnold, F. Niccolucci, K. Mania (eds), Conference Proceedings, 7th VAST International Symposium on Virtual Reality, Archaeology and Cultural Heritage 2006, Baltimore, Maryland, USA, Eurographics.

Papadopoulos, C and Earl, G. 2009. Structural and Lighting Models for the Minoan Cemetery at Phourni, Crete, in: K. Debattista, C. Perlingieri, D. Pitzalis, and S. Spina (eds), Conference Proceedings, 10th VAST International Symposium on Virtual Reality, Archaeology and Cultural Heritage 2009.

Pinchbeck, D.M. and Stevens, B. 2005. Presence, Narrative and Schemata. In Proceedings of Presence 2005: The 8th International Workshop on Presence. University College London, UK, 21-23rd September. 221-26

Prince, S. 1996. True Lies: Perceptual Realism, Digital Images, and Film Theory. Film Quarterly, Vol. 49, No. 3. (Spring, 1996), pp. 27-37 
Schleicher, R., Spors, S., Jahn, D. and R. Walter. Gaze as a measure of sound source localization. In AES 38th International Conference on Sound Quality Evaluation, June 2010.

Snow, C.P. 1960. The Two Cultures. Cambridge: Cambridge University Press

Stiny G 1975 Pictorial and Formal Aspects of Shape and Shape Grammars Birkhauser, Basel

Thomas, J. 2004: Archaeology and Modernity. London: Routledge.

Ware, c. 2004. Information Visualization: Perception for Design - Interactive Technologies (Second Edition). Morgan Kaufmann

Watson, A. 2006. (Un)intentional sound? Acoustics and Neolithic monuments. In Scarre, C. and Lawson, G. (eds) Archaeoacoustics. Cambridge: McDonald Institute Monographs

Weidlich, A. and Wilkie, A. 2008. Modeling aventurescent gems with procedural textures. In proceedings of the spring conference on computer graphics (SCCG). pp1$8 \mathrm{ACM}$

Zubrow, E. 2010. From Archaeology to I-archaeology: Cyberarchaeology, paradigms, and the end of the twentieth century. In Forte, M. (ed.) Cyber-archaeology. Archaeopress: Oxford 